2 Shulman MS, Brodsky JB, Colby $T$, Mark JED. The relationship of $\mathrm{FIO}_{2}$ to postoperative mortality in patients who have received bleomycin. Anesth Analg 1984; 63: 274.

3 Goldiner PL, Carlon GC, Cvitkovic E, Schweizer O, Howland WS. Factors influencing postoperative morbidity and mortality in patients treated with bleomycin. Br Med J 1978; 1: 1664-7.

4 Yelderman $M$, New $W, J r$. Evaluation of pulse oximetry. Anesthesiology 1983; 59: 349-52.

\section{Hypertension associated with cardiopulmonary bypass}

To the Editor:

In the recent article by Townsend et al ${ }^{1}$ the authors conclude that the renin-angiotensin system is not the primary mediator of cardiopulmonary bypass associated hypertension, at least during fentanyl anaesthesia. In that study, as outlined in the method, all patients were anaesthetised with a single bolus of fentanyl and reccived halothane or enflurane if hypertension occured prior to cardiopulmonary bypass. After institutions of cardiopulmonary bypass no further anaesthestic was given. Recent studies ${ }^{2,3}$ have indicated that fentanyl levels on cardiopulmonary bypass may fall to subtherapeutic levels very quickly. One study has demonstrated that this may be a result of binding of fentanyl to certain membrane oxygenators and siliconized tubing. ${ }^{3}$ In the absence of any other anaesthetic agent, I question therefore whether $\mathrm{CPB}$ associated hypertension is hypertension associated with lack of anaesthesia.

I would suggest that any study which involved the use of fentanyl as a primary anaesthetic agent during cardiopulmonary bypass is subject to the possibility of patients having inadequate anaesthesia and massive sympathetic output may occur on that basis. Perhaps studies including fentanyl as a major component of anaesthesia during bypass should include drug levels as part of that study to demonstrate whether anaesthesia is adequate during the period of study.
Gerald V. Goresky MD FRCP(C)

Department of Andesthesia

Alberta Children's Hospital

Calgary, Alberta

REFERENCES

1 Townsend GE, Wynands JE, Whalley $D G$, Wong $P$, Bevan DR. Role of Renin-Angiotensin System in Cardiopulmonary Bypass Hypertension. Can Anaesth Soc J 1983; 31: 160-5.

2 Bentley JB, Conahan TJ, Cork RC. Lung Sequestration of Fentanyl During Cardiopulmonary Bypass Anesthesiology 1982; 57: A244.

3 Koren G, Crean P, Goresky G, et al. Imeversible binding of Fentanyl to the Cardiopulmonary Bypass. Anesth Analg 1984; 63: 236.

\section{$R E P L Y$}

We are grateful for the opportunity to reply to $\mathrm{Dr}$. Goresky's letter. The abstracts he quotes provide convincing evidence of the sequestration of fentanyl in the lungs and in the membrane oxygenator during cardioput monary bypass (CPB) and explain the substantial decrease of plasma fentanyl concentration that has been observed during $C P B$. We use bubble rather than membrane oxygenators during $C P A$ and, in a previous study,' did not see any dramatic decrease in plasma fentanyl concentration with institution of $C P B$

We agree that the most likely cause of the hypertension in our patients was an adrenergic response which. perhaps, could have been diminished by administration of additional anaesthesia. However, the purpose of our study was to determine whether the renin-angiotensin system also had a causative role in CPB-associated hypertension. Our results suggest it does not.

We dispute whether it is possible to determine the adequacy of anaesthesia by measuring plasma fentanyl concentrations. When fentanyl is administered as a continuous infusion there is a tendency for higher plasma levels to be associated with a reduction in the incidence of hypertension during CPB. However, the relarionship is inconsistent and unpredictable and we suspect, ${ }^{2}$ like others. ${ }^{3}$ that it is not possible to block the response to noxious stimuli complerely, at least at fentanyl doses used in clinical practice.

G.E. Townsend MD FRCr(C)

J E. Wynands MD FRCP(C)

D.G. Whalley MB FRCP(C)

D.R. Bevan MB MRCP FFARCS

Department of Anaesthesia

Royal Victoria Hospital

Montreal, Quebec

REFERENCES

1 Wynands JE, Townsend GE, Wong $P$, Wholley $D C$. Srikant $C B$, Patel YC. Blood pressure response and plasma fentanyl concentrations during high- and very 
high-dose fentanyl anesthesia for coronary antery surgery. Anesth Analg 1983; 62: 661-5.

2 Wynands JE, Wong $P$, Townsend GE, Sprigge JS, Whalley $D G$. Narcotic requirements for intravenous anesthesia. Anesth Analg 1984; 63: 101-5

3 Sonntag $H$, Larsen $R_{1}$ Hilfiker $O$, Kettler D, Brockschneider $B$. Myocardial blood flow and axygen consumption during high-dose fentanyl anesthesia in patients with coronary artery disease. Anesthesiology 1982; 56: 417-22.

\section{Diagnosis of malig- nant hyperthermia}

To the Editor:

Rosenberg and Gronert ${ }^{1}$ have recently challenged the diagnosis of malignant hyperthermia (MH) as reported by Grinberg et al. ${ }^{2}$ They believe that Grinberg et al. had insufficient data to support their contention that the episodes reported by them were MH. Rosenberg and Gronert feel that labeling a patient $\mathrm{MH}$ susceptible has far-reaching implications in the medical care of such patients and that the diagnosis should be made with care. It is difficult to disagree with them on this latter point.

However, to err the other way and fail to make the clinical diagnosis usually leads to a worse outcome than incorrectly labeling someone $\mathrm{MH}$ susceptible. There are still too many deaths occurring annually from $\mathrm{MH}$. In many of these cases there has been sufficient data to make the presumptive diagnosis of $\mathrm{MH}$, yet the anaesthetists fail to make the proper diagnosis for a variety of reasons. One of the most common reasons is an unwilling. ness to accept the diagnosis of $\mathrm{MH}$. There are many anaesthetists who do not believe in the syndrome. All too frequently there is a willingness to place the blame on human error as a cause of the deaths. One of the reasons for this is that many authorities still insist that MH is a rare condition and should have a low priority in the differential diagnosis of complications of anaesthesia. In those areas of the United States where there is an emphasis on the diagnosis of $\mathrm{MH}$, the mortality from it has fallen to almost zero. In other areas where there is hesitance to make an early diagnosis, the mortality rate is still quite high. These latter areas of the country seem to centre around spheres of influence which convince anaesthetists that $\mathrm{MH}$ has a low priority as a cause of death.

A second major reason for $\mathrm{MH}$ deaths is the unwillingness of anaesthetists to properly monitor their patients, particularly the body temperature. I don't understand the hesitance to use simple moni- tors such as those used for body temperature when many anaesthetists will go to great lengths to insert Swan-Ganz catheters, arterial catheters, etc. In the majority of the cases of $\mathrm{MH}$ in which there has been a major complication, there has been evidence that the patient's temperatures were rising. To my amazement, some anaesthetists are still observing body temperatures rising to extraordinarily high levels without considering the diagnosis of $\mathrm{MH}$.

$\mathrm{MH}$ is a clinical syndrome. All of the diagnostic techniques have been developed from patients of animals who developed the clinical syndrome. To my knowledge no one has developed a test which can assure the diagnosis of $\mathrm{MH}$. Until the supporters of the muscle biopsy prove that they can accurately make the diagnosis of $\mathrm{MH}$ in everyone, the diagnosis must be made on a clinical basis. Our primary goal must be to reduce the mortality and morbidity from MH. It is far better to overdiagnose MH than to underdiagnose it. To my knowledge there has never been a death from $\mathrm{MH}$ in a known susceptible patient when appropriate precautions have been used. The same cannot be said for the undiagnosed patient, or worse yet, the suspected susceptible patient who had a procedure performed without adequate precautionary measures.

Occasionally patients may be upset that they are labeled incorrectly. This is the exception rather than the rule. Usually they are more concerned that someone who is unfamiliar with MH will be taking care of them.

I am appalled at the number of anaesthetists who are unfamiliar with the MH clinical syndrome or do not even know that it exists. Likewise, it is generally not appreciated by those who are familiar with the syndrome that it is more likely to be seen and diagnosed in the postoperative period than in the operative period. In my opinion we need reports such as that by Grinberg et al, to help us further ellucidate the diagnosis of $\mathrm{MH}$ and to bring it to the attention of the medical profession. I agree with them in their reply to Drs. Rosenberg and Gronert.

Daniel W. Wingard MD

Department of Anesthesiology

University of Nebraska Medical Center

Omaha, Nebraska

\section{REFERENCES}

1 Rosenberg $H$, Gronert GA. Postoperative malignant hyperthermia. Can Andesth Soc J 31: 115-6, 1984.

2 Grinbery $R$, Edelist G, Gordon A. Postoperative malignant hyperthermia episodes in patients who received "safe" anacsthetics. Can Anacsth Soc $J 30$ : 273-6, 1983. 